\section{Adult Dental Health Survey 2009: transformations in British oral health 1968-2009}

\author{
J. G. Steele, ${ }^{1}$ E. T. Treasure, ${ }^{2}$ I. O'Sullivan, ${ }^{3}$ J. Morris ${ }^{4}$ and J. J. Murray ${ }^{5}$
}

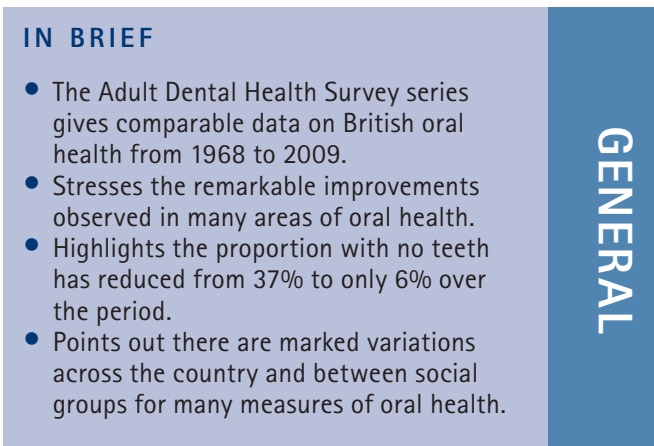

\begin{abstract}
This series of four papers reports and interprets the findings of the Adult Dental Health Survey (ADHS), 2009, published in early 2011. This is the fifth in a series of surveys repeated every decade since 1968. The evolution of the surveys and the way the supporting methodology has changed to meet the changing needs and circumstances over the last 40 years is described. In 1968, 37\% of adults in England and Wales were edentate. By 2009, only 6\% of the combined population of England, Wales and Northern Ireland were edentate. Among the dentate in 1968, there were a mean of 21.9 teeth. By 2009, not only had the dentate increased by 30 percentage points as a fraction of the population, but the number of teeth in this group had also increased by nearly four teeth on average to 25.7. There were significant variations in oral health according to geography and social variables and smaller differences according to sex. The retention of 21 or more teeth is widely used as a way of defining a minimum functional dentition. The proportion of adults with $21+$ teeth increased from $73 \%$ in 1978 to $86 \%$ in 2009. Further huge improvements are projected as younger generations age, assuming future tooth loss continues at current low rates. We might expect that over 90\% of those aged 35-44 in 2009 have a realistic prospect of retaining a functional natural dentition of 21 or more teeth by age 80 .
\end{abstract}

\section{INTRODUCTION}

This paper is the first of four in a series, which aims to report and interpret the findings of the fifth Adult Dental Health Survey (2009) published in March 2011 (http://www.ic.nhs.uk/statistics-and-datacollections/primary-care/dentistry/ adult-dental-health-survey-2009--summary-report-and-thematic-series). It examines oral health in Britain in the context of this series of surveys first conducted in 1968 and repeated every decade since. The text and analysis for all four papers is largely drawn from the original reports ${ }^{1-5}$

\footnotetext{
${ }^{1 *}$ Newcastle University, School of Dental Sciences and Centre for Oral Health Research, Framlington Place, Newcastle upon Tyne, NE2 4BW; ${ }^{2}$ Deputy Vice-Chancellor/Professor of Dental Public Health, Vice-Chancellor's Office, Cardiff University, Main Building, Park Place, Cardiff, CF10 3AT; ${ }^{3}$ Assistant Divisional Director, Social Survey Division, Office for National Statistics, Cardiff Road, Newport, NP10 8XG; ${ }^{4}$ School of Dentistry, University of Birmingham, St Chad's Queensway, Birmingham, B4 6NN; ${ }^{5}$ Emeritus Professor, Newcastle University, School of Dental Sciences and Centre for Oral Health Research, Framlington Place, Newcastle upon Tyne, NE2 4BW

${ }^{*}$ Correspondence to: Professor Jimmy Steele Email: Jimmy.Steele@Newcastle.ac.uk
}

Accepted 4 October 2012

DOI: 10.1038/sj.bdj.2012.1067

${ }^{\circledR}$ British Dental Journal 2012; 213: 523-527 but the content is adapted and interpreted for a specifically dental audience.

The surveys have evolved over the years to meet changing needs and circumstances, not least the profound changes in oral health, which they themselves have described. To put the 2009 survey in context it is probably helpful to go right back to the origins of the programme and that first survey in 1968.

The National Health Service (NHS) was instituted in 1948 but twenty years later, nobody knew what effect the NHS was having on dental health. The Ministry of Health at the time commissioned a team of dental specialists, based at the London Hospital Medical College, and survey specialists from Government Social Survey, 'to provide information about the dental health of the community generally and to establish whether there was any regional variation in dental health. ${ }^{1}$ This survey, organised on a national scale and based on a random sample, enabled information to be obtained concerning the attitudes and dental state of a complete cross-section of the community, including the proportion of the population who rarely seek dental attention. Britain was not alone at this time, the US had already collected national data on the oral health of its population as part of its disease surveillance programme ${ }^{6}$ but the British survey was unique in its ability to link social with clinical data.

\section{SURVEY METHODS IN 1968}

The inquiry in 1968 consisted of an interview followed at a later stage by a dental examination. Both were conducted in the person's own home, but at different times. The persons to be interviewed were selected at random from the electoral register for England and Wales. The initial sample was just over 3,000. A total of 125 interviewers and 44 dentists were involved in the fieldwork, which was completed in May and June 1968. Government Social Survey interviewers made contact with individuals selected for the sample and obtained information about dental habits, attitudes and the interviewees' assessment of his/her own dental health. At the end of the interview, the interviewee was asked if they would be willing to have a dental examination in their own home. If permission was given, the interviewer made arrangements to return with the dentist. In 1968 interviews were obtained with $85 \%$ of the 
sample and $91 \%$ of those were dentally examined (2,658 adults). The same basic approach has been used in all subsequent surveys, including the 2009 survey.

In 1968, a two-stage sample design was used. A sample of 50 constituencies out of the 547 in England and Wales comprised the first stage units. From each constituency about 66 named persons were selected from the 1968/1969 electoral register. At that time the electoral register only included people aged 21 years or more. It was therefore necessary to also obtain a sample of private households and select all those aged 16-20 years from such households.

\section{RESULTS FROM THE 1968 SURVEY}

\section{Edentulousness in 1968}

Seen from the perspective of 2012, the finding that in 1968 37\% of adults aged 16 and over had no natural teeth seems astounding. By comparison, national data for the USA in 1961/2 revealed only $18.1 \%$ were edentulous. ${ }^{1}$ There was considerable regional variation between London and the South east (28\%) and the North (46\%).

People who had lost all their natural teeth were asked some details about the circumstances of their loss. These questions were confined to people who had lost all their natural teeth within the previous 20 years; that is during the lifetime of the NHS. It is sobering to realise that in 1968 , $34 \%$ of all adults had 21 or more teeth extracted in one sitting in order to prepare for complete dentures, and for those who did not have a partial denture, the proportion was 54\% (Table 1). There was considerable regional variation and the suggestion of a cultural dimension with more large scale extractions being carried out in the North than elsewhere. This gives us an insight into the patterns of care in the early NHS and the legacy was the large proportion of edentate people in 1968.

\section{The effect of regional variation and attendance in 1968}

In 1968 , only 1,694 of the adults interviewed aged 16 years and over, had any natural teeth (dentate sample). In order to examine regional variation on dentate adults, much of the data were presented in two age groups, 16-34-year-olds and 35 years and over. A comparison of dentate adults aged 16-34 years who were regular attendees from London and the South East (the 'best') and irregular attendees from the North (the 'worst') yielded some interesting results (Table 2 shows the data for some selected teeth). The 'London Regulars' had more standing teeth than the 'North Irregulars', but there was a higher proportion of people in the North with sound and untreated teeth than those in London, who had many more restored teeth, particularly in the premolar and molar region. The report commented; 'in resolving this paradox it is necessary to consider the nature of the dental examination....in summary the examination was carried out in the home and the dental examiner was making a clinical assessment of decay. He did not have the help of an X-ray and, in order to ensure uniformity of recording with the other examiners, only obvious decay lesions were recorded'. The inference was that a failure of caries diagnosis (and therefore unmet need) in non-attendees partly explained the difference. Also implicit in this explanation was that there was a difference in the attitudes of patients to dental health and treatment, and that a difference in treatment given by dentists was also contributory. The report concluded 'it cannot therefore be stressed too forcefully that attendance pattern and treatment play a very large part indeed in people keeping their natural teeth'. The possibility that relatively healthy teeth may have been restored was not noted as a possibility. Echoes of these findings are present in the 2009 data.

\section{Conclusion: limitations of the 1968 survey.}

The 1968 survey was a trailblazer in national dental surveys in that it combined both a clinical and 'socio-dental' component, but even by the standards of the time it was not faultless. The size of the sample was compromised by the high proportion of adults who were already edentulous, so the original sample was too small to undertake the sort of detailed breakdown that was possible subsequently. The low number in the older age groups made it impossible to assess regional variation and attendance patterns in ten year age groups. Also, although attempts were made to measure plaque, calculus, gingivitis and periodontal pocketing, assessments did not allow the data to be presented in terms of periodontal indices that were being developed in the 1960s.

\section{SURVEY METHODS 1978-2009}

\section{Developments in the methods} of assessment for the 1978 and 1988 surveys

The United Kingdom health departments commissioned the 1978 survey from the Office of Population Censuses and Surveys $(\mathrm{OPCS})^{2,3}$ and continuity was maintained by Miss Jean Todd, who had been a co-author of the 1968 report. The development of the criteria used in the dental examination and the training of the survey dental examiners was undertaken by Professor Roger Anderson from the Community Dental Health Unit at the University of Birmingham Dental School, who had been involved in the first survey in 1968. Colleagues from Newcastle Dental School were also involved. The Electoral Roll was again used to obtain a random sample but the size of the sample was increased so as to obtain more information about adults with teeth.

In 1968 dentists were recruited from dental schools and from an advertisement in the dental press. By 1978, a cohort of dental examiners from the Community Dental Service had been trained and calibrated and had participated in the national survey of children's dental health in 1973, so these examiners were involved in 1978. It was also decided that the dental examination would only be carried out on dentate adults, as the extra information that could be gained from examining edentulous subjects was felt to be minimal. The size of the sample was increased to 6,679 and interviewers were achieved with 5,967 adults, of which 3,495 adults were examined. A comparison of tooth conditions in 16-34-year-olds in 1968 and 1978 showed that relatively little change had occurred in this age group in the intervening ten years.

The same academic team was involved in the 1988 survey. ${ }^{4}$ The size of the sample needed to be sufficient to measure changes in dental health since 1978 and to be able to examine regional variation. All of the four home nations were involved, with enhanced samples in Scotland, Wales and Northern Ireland to allow individual reporting by nation. 
During the intervening ten years there had been major developments in survey methods, one of which was to change from using the electoral register as a sampling frame to using the postcode address file for most survey samples. The main advantage of the postcode address file is that it is computerised; the main disadvantage is that it contains addresses, but not names, of individuals living at the addresses. The total sample was 7,252 addresses and an interview was obtained for 6,825 adults (94\%). Sixty-four dental examiners seconded from the community dental service completed 4,331 dental examinations (82\% of those adults with teeth). Many of the features of the dental examination were identical to those in the 1968 and 1978 surveys, so as to be able to measure change over a 20 year period. Some new features were added to reflect various issues that were currently of concern, such as the condition of the root surfaces of natural teeth. Part of the dental examination was expanded so that more attention could be paid to periodontal disease in adults and to the increasing amount of complex dentistry (crowns and bridges) that was now evident in the adult population.

\section{Further developments for the 1998 survey}

By 1998, the team responsible for the national survey comprised the Social Survey Division of the Office of National Statistics in collaboration with the Dental Schools of Birmingham, Dundee, Newcastle and Wales as well as the Central Survey Unit of the Northern Ireland Statistics Research Agency. ${ }^{5}$ In total, 6,204 adults were interviewed and 3,817 dental examinations were carried out by 75 dentists from the Community Dental Service and health authorities of the NHS.
Further developments were incorporated into the 1998 adult dental health survey to reflect much improved understanding of oral health and disease.

Before the 1998 survey only overtly cavitated lesions were recorded as carious. In 1998, the diagnosis of caries was expanded to include visual evidence, to ensure a more complete assessment of this disease but cavitated lesions were recorded separately to allow comparison with previous surveys.

For the first time an assessment was made of adhesive bridges and veneers, so that there was scope to record new technologies in a meaningful way.

The assessment of periodontal disease was expanded to bring it in line with contemporary measurement methods including the concept of loss of attachment as well as pocketing.

A measurement of plaque, a matter of contention in 1968, was included in the 1998 survey. This was important if improvements in oral hygiene and reduction in risk were to be measured, particularly with ageing dentate populations at risk of root caries as well as periodontal disease.

The functionality of the occlusion was recorded by determining the proportion of the dentate population with 21 or more teeth and the distribution of functioning teeth, emphasising the trend towards the concept of a functional dentition.

More comprehensive sociological measures were introduced, including the newly developed 14-item version Oral Health Impact Profile (OHIP), to ensure a patientbased measure of health, rather than just focusing on disease.

\section{Arrangements for the 2009 survey}

By 2009, the world of health statistics was an altogether more complicated place. The 2009 survey was commissioned by the NHS Information Centre for health and social care and was conducted on behalf of the Department of Health in England, the Welsh Assembly Health Department, and the Department of Health and Personal Services in Northern Ireland only; Scotland decided not to participate in the 2009 survey making UK comparisons impossible. The survey was managed by the Office for National Statistics working in consortium with the National Centre for Social Research, the Northern Ireland Statistics and Research Agency, and dental experts from the Universities of Birmingham, Cardiff, Dundee, Newcastle, and University College London.?

The sample size for the survey was much bigger; 13,400 households (1,150 in each English Strategic Health Authority and Wales and 750 households in Northern
Table 1 The number of teeth extracted to render the subject edentate in 1968, among those who reported having their teeth removed in the previous 20 years (from 1968 report)

\begin{tabular}{|l|l|l|l|} 
& \multicolumn{3}{|l}{$\begin{array}{l}\text { Adults in England and Wales who reported the last of their teeth being } \\
\text { removed in the previous 20 years }\end{array}$} \\
\hline & With partial denture & Without partial denture & All \\
\hline $\mathbf{1 - 1 1}$ teeth & $52.7 \%$ & $12.0 \%$ & $32.2 \%$ \\
\hline $\mathbf{1 2 - 2 0}$ teeth & $33.3 \%$ & $34.0 \%$ & $33.6 \%$ \\
\hline 21 or more teeth & $14.0 \%$ & $54.0 \%$ & $34.2 \%$ \\
\hline Base & 264 & 268 & 532 \\
\hline
\end{tabular}

Table 2 Percentage of individual tooth types (FDI notation) that were sound, filled, decayed and missing in 1968, comparing data for attendees in the south east of England to non-attendees in the north of England. Note the higher proportions of sound teeth in non-attendees from the north of England

\begin{tabular}{|c|c|c|c|c|c|c|c|c|}
\hline \multirow[b]{2}{*}{ Tooth } & \multicolumn{2}{|c|}{ Percentage sound } & \multicolumn{2}{|c|}{ Percentage filled } & \multicolumn{2}{|c|}{ Percentage decayed } & \multicolumn{2}{|c|}{ Percentage missing } \\
\hline & $\begin{array}{l}\text { SE regular } \\
\text { attendees }\end{array}$ & $\begin{array}{l}\text { North } \\
\text { non-attendees }\end{array}$ & $\begin{array}{l}\text { SE regular } \\
\text { attendees }\end{array}$ & $\begin{array}{l}\text { North } \\
\text { non-attendees }\end{array}$ & $\begin{array}{l}\text { SE regular } \\
\text { attendees }\end{array}$ & $\begin{array}{l}\text { North } \\
\text { non-attendees }\end{array}$ & $\begin{array}{l}\text { SE regular } \\
\text { attendees }\end{array}$ & $\begin{array}{l}\text { North } \\
\text { non-attendees }\end{array}$ \\
\hline 17 & $5 \%$ & $30 \%$ & $79 \%$ & $18 \%$ & $5 \%$ & $29 \%$ & $11 \%$ & $23 \%$ \\
\hline 21 & $65 \%$ & $73 \%$ & $25 \%$ & $11 \%$ & $2 \%$ & $10 \%$ & $8 \%$ & $6 \%$ \\
\hline 24 & $20 \%$ & $51 \%$ & $63 \%$ & $17 \%$ & $6 \%$ & $11 \%$ & $11 \%$ & $21 \%$ \\
\hline 35 & $54 \%$ & $57 \%$ & $26 \%$ & $10 \%$ & $3 \%$ & $12 \%$ & $17 \%$ & $21 \%$ \\
\hline 42 & $93 \%$ & $96 \%$ & $2 \%$ & $1 \%$ & $1 \%$ & $3 \%$ & $1 \%$ & $0 \%$ \\
\hline
\end{tabular}


Ireland). The reason for the larger sample was to allow valid data for each of the ten English Strategic Health Authorities as well as for Northern Ireland and Wales. This was a reflection in part of the way that dental services were provided, from a reactive system where dentists provided care in response to need and demand, towards a system where local health organisations commissioned care and required data with which to work.

Data collection for the survey took place between October 2009 and April 2010, and the final household interview response rate was $60 \%$. One of the striking changes from the early surveys has been the declining response rate. The lower response means that there has been a greater dependence on weighting the 2009 data to control for response bias and variations between respondents, than in previous $\mathrm{ADH}$ surveys. Any resulting differences should be minimal but trends data in particular rely on very precise estimates so some caution should be exercised when interpreting these results. Although ADH surveys are cross-sectional, when taken together the survey series does allow for changes within generations to be tracked.

In 2009, the salaried services undertook the examinations once again but changes to services, not least commissioning arrangements, which saw local services with treatment targets to meet, was putting pressure on local services and recruitment of examiners was becoming problematic. Nevertheless 77 dentists collected data. A total of 11,380 individuals were interviewed and 6,469 adults were examined, making this the largest ever epidemiological survey of adult dental health in the British Isles and one of the biggest comprehensive oral health surveys in the world.

\section{RESULTS 2009 SURVEY}

Detailed results will be presented in subsequent papers, but first, two key aspects of oral health will be summarised, because they illustrate the scale of the change over the last 40 years; edentulousness and the number of standing teeth. These changes provide a context for the more detailed data that follow in subsequent papers.

\section{Total tooth loss 1968 to 2009}

In 1968 , with $37 \%$ of the population of England and Wales edentate, the idea that

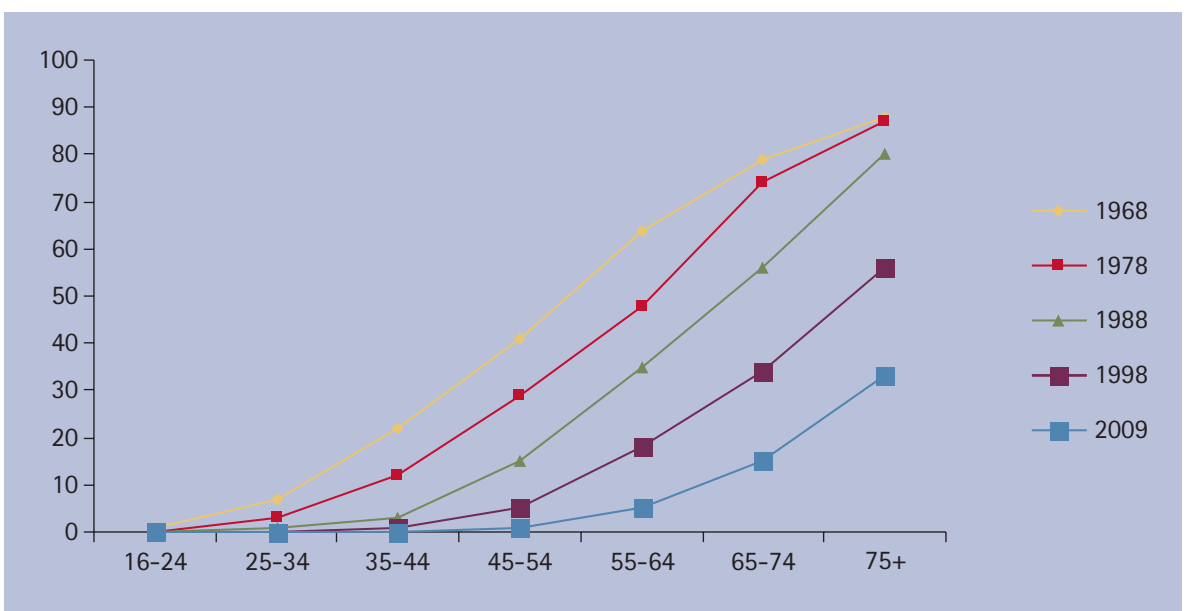

Fig. 1 Percentage edentulous by age-group 1968-2009. For 1968-1988 the data are for England and Wales and for 1998-2009 for England only. The inclusion of data from Wales for 1968-1988 reflects the presentation of the older data but makes very little difference to the overall percentages. Data from Scotland and Northern Ireland are omitted from this plot because of their variable inclusion in the national surveys

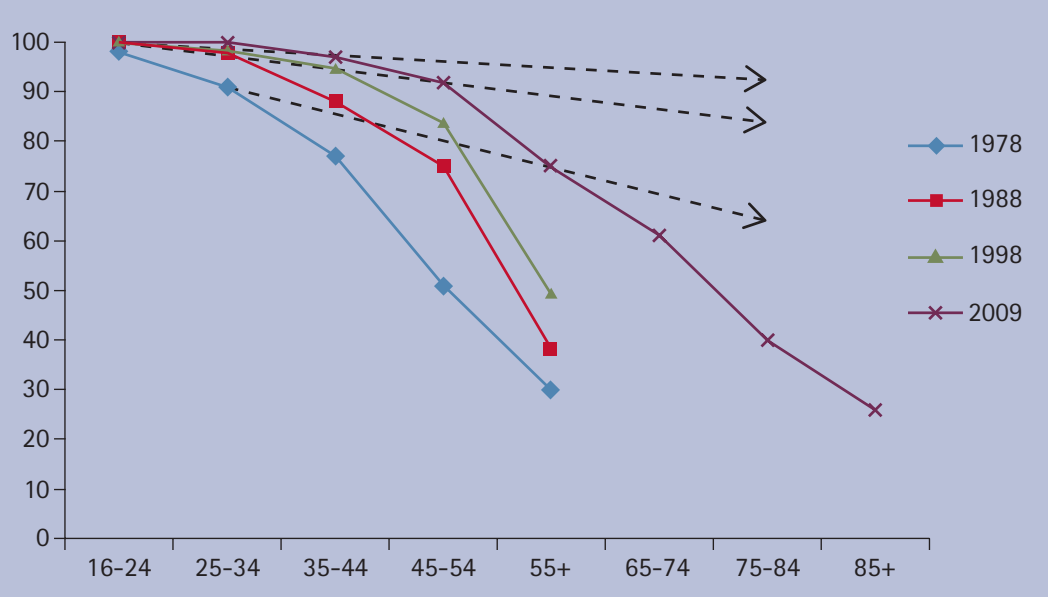

Fig. 2 The proportion of people with 21 or more natural teeth (y axis) by age, 1978-2009. For 1978-98 only data up to age 55+ are presented but for 2009 data are included in ten year bands up to $85+$. The dashed arrows indicate the approximate, but very different trajectories for those who were 35-44 (top), 45-54 middle and 55-64 (lower) in 2009 with their expected prevalence of $21+$ natural teeth by age 75-84 indicated by the arrow point. This assumes a linear trajectory but note that for those aged 55-64 in 2009 there is the suggestion that the trajectory may have deteriorated in the previous decade and the rate at which people drop below the $21+$ teeth threshold has increased

more than half of people aged 85 or more could retain some natural teeth would have seemed unthinkable. Yet this was the case in 2009. The transformation in the population's oral health, first observed confidently in the 1988 ADHS, has been extensive. Scotland opted out in 2009, but there is no real reason to expect that the changes there have been substantially different from the rest of the UK.

In 2009, 94\% of the combined populations of England, Wales and Northern Ireland were dentate, that is they had at least one natural tooth. The proportion of adults in England who were edentate (no natural teeth) has fallen by 22 percentage points in 30 years from 28\% in 1978 to 6\% in 2009 (Fig. 1). The scale of this reduction is worthy of note. The 1998 survey gave predicted future levels of total tooth loss for 2008 (8\%), 2018 (5\%) and 2028 (4\%). In fact, the results for the current study are closer to the 2018 prediction than the 2008 expectation and this acceleration in change should merit some attention.

Although the percentage of people who are edentate is small, it still accounts for approximately 2.7 million adults across England, Wales and Northern Ireland. Unsurprisingly, given the cumulative effects of dental disease and tooth loss, there was a strong relationship between 
increasing age and total tooth loss. The proportion of adults with no teeth increased more or less exponentially with age group; however, for the first time in the survey series the majority of adults in each age group (even those over 85 years) were dentate (Fig. 1). The fact that approximately half of the very old have retained some natural teeth has important implications in terms of the potential for good oral function, as well as service implications related to the continuing maintenance of natural teeth in these age groups.

\section{Number of natural teeth 1968-2009}

In 1968, the proportion of the population with no natural teeth was a valid and realistic indicator of the oral health of the population. With the changes described above, that is no longer the case and a myriad of additional measures are required to understand the health of the population. The next two articles in the series will explore these. However, a simple count of the number of teeth can give a robust and straightforward indicator of the population's oral health and how it has changed and so this is covered here as arguably the clearest measure of oral health outcome there is.

In 1968, the proportion of people with any teeth was much smaller than in 2009, but even when only the dentate were considered, the mean number of teeth was only 21.9. In 2009, the overall mean number of teeth among dentate adults was 25.7 , with the majority of dentate adults (60\%) having between 27 and 32 teeth. The number of teeth among dentate adults was strongly associated with age, reflecting the one-way nature of tooth loss and the accumulated effects of disease and treatment over the life course. For example, dentate 16-24-year-olds had 28.6 teeth on average compared with 23.2 teeth among dentate 55-64-year-olds and 14.0 among dentate adults aged 85 and above.

The difference in the average number of teeth between dentate men and women was small but significant, 25.8 compared with 25.5 respectively. The average number of teeth dentate adults had also varied by country (25.7 in England, 24.3 in Wales and 25.1 in Northern Ireland), by strategic health authority (SHA) (highest in London with 27.0 teeth and lowest in the South West with 24.8); and the socio-economic classification of the household (dentate adults from managerial and professional occupation households had 26.6 teeth compared with dentate adults from routine and manual occupation households who had 24.7).

\section{Retention of $\mathbf{2 1}$ or more natural teeth 1978-2009}

The retention of 21 or more natural teeth is widely used to define the minimum number of teeth consistent with a functional dentition for most people and it has been used in this way in previous ADH surveys. While this figure may be viewed as arbitrary, there is evidence to indicate that 21 or more natural teeth enable most dentate individuals to eat what they want in comfort without the need for a removable partial denture. In $2009,86 \%$ of dentate adults had 21 or more natural teeth. This proportion fell significantly as age increased, again reflecting loss of teeth through life. All dentate adults aged 16-24 years had 21 or more natural teeth compared with $91 \%$ of dentate 45-54-yearolds and just $40 \%$ of dentate adults aged 75-84. This decline should be seen in the context of the similar fall in the proportion of dentate adults with age. Among adults aged 85 and above only 53\% were dentate and of these adults $26 \%$ had 21 or more natural teeth. These older dentate adults with enough natural teeth remaining to enable a functional dentition represent 14\% of all adults aged 85 and over. However, we can expect this to change in years to come

The proportion of dentate adults with 21 or more natural teeth showed significant variation around the country. It was highest in England (86\%) followed by Northern Ireland (85\%) and was lowest in Wales (80\%). There was also significant variation between English SHAs with the highest rate in London (91\%) and the lowest in the North East and West Midlands SHAs (82\%). Finally, a clear socio-economic gradient was also evident; $92 \%$ of dentate adults from managerial and professional occupation households had 21 or more natural teeth, compared with 79\% among dentate adults from routine and manual occupation households.

Figure 2 shows the trends in retention of 21 or more teeth since 1978 by age. There is inevitably a reduction in the proportion with age, evident in every survey. However, that proportion is increasing and by following age cohorts through we can start to project the likely prospects of younger generations retaining a natural functional dentition of 21 or more teeth. This clearly illustrates that, assuming basically linear trends (which may not be reliable in older age), the prospects for the three successive age groups (25 year-olds through to 64-year-olds from 2009) appear to improve substantially from the position of the current 75-84-year-olds, with potential benefits in the form of good diet, nutrition, quality of life and overall health.

\section{CONCLUSION}

The adult dental health survey series is unique in the world and chronicles a remarkable change in oral health in the United Kingdom spanning 40 years, but also a profound change in the wider environment of health, healthcare and attitudes. The clinically assessed status of people in England, Wales and Northern Ireland will be described, and the magnitude and direction of changes in common oral conditions will be considered in the next paper in the series.

This study was commissioned by the NHS Information Centre for health and social care and was conducted on behalf of the Department of Health in England, the Welsh Assembly Health Department and the Department of Health, Social Services and Public Safety in Northern Ireland. The survey was managed by the Office for National Statistics with a major contribution from The National Centre for Social Research. We would like to thank all of the specialists and colleagues who contributed from both organisations. Our thanks also go to the field teams of dentists and recorders who undertook the examinations and interviews around the country, whose enthusiasm and work ethic often extended beyond the call of duty. Not least we are grateful to the 11,380 individuals who gave their time as survey participants.

1. Gray P G, Todd J E, Slack G L, Bulman J S. Adult dental health in England and Wales in 1968. London: HMSO, 1970

2. Todd J E, Walker A M, Office of Population, Censuses and Surveys. Adult dental health: volume 1, England and Wales 1968-1978. London: HMSO, 1980.

3. Todd J E, Walker A M, Dodd P. Adult dental health: volume 2, UK 1978. London: HMSO, 1982.

4. Todd J E, Lader D. Adult dental health 1988, United Kingdom. London: HMSO, 1988.

5. Kelly M, Steele J, Nuttall $\mathrm{N}$ et al. Adult dental health survey: oral health in the United Kingdom in 1998. London: The Stationery Office, 2000.

6. Johnson E S, Kelly J E, VanKirk L E. Selected dental findings in adults by age, race, and sex; United States - 1960-1962. Vital Health Stat 11 1965; 11: $1-35$

7. O'Sullivan I, Lader D, Beavan-Seymour C, Chenery V. Fuller E, Sadler K. Foundation report: adult dental health survey 2009 (technical information). London: The Health and Social Care Information Centre, 2011. Online report available at http://www.ic.nhs.uk/webfiles/publications/007_Primary_Care/Dentistry/dentalsurvey09/ AdultDentalHealthSurvey 2009 FoundationReporttechnical information.pdf (accessed October 2012). 